Document downloaded from:

http://hdl.handle.net/10251/102487

This paper must be cited as:

Martinez Cano, L.; Lucas Borja, A.; Boria Esbert, VE.; Belenguer, A. (2017). Highly Versatile Coplanar Waveguide Line With Electronically Reconfigurable Bandwidth and Propagation Characteristics. IEEE Transactions on Microwave Theory and Techniques. 65(1):128-135. doi:10.1109/TMTT.2016.2613526

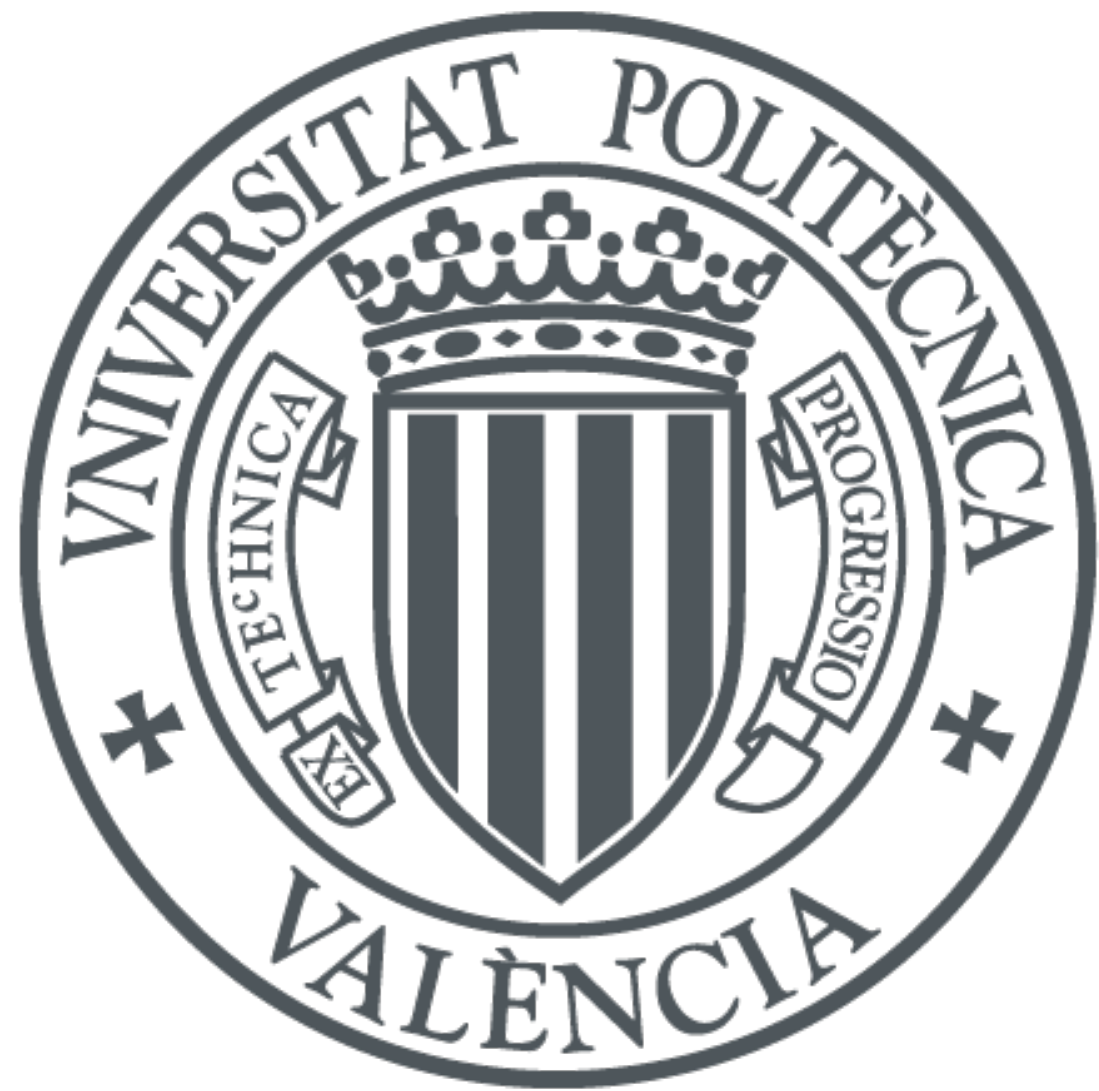

The final publication is available at

http://doi.org/10.1109/TMTT.2016.2613526

Copyright Institute of Electrical and Electronics Engineers

Additional Information 


\title{
Highly Versatile Coplanar Waveguide Line with Electronically Reconfigurable Bandwidth and Propagation Characteristics
}

\author{
Leticia Martínez, Alejandro L. Borja, Member, IEEE, Vicente E. Boria, Senior Member, IEEE, \\ and Angel Belenguer, Senior Member, IEEE,
}

\begin{abstract}
This paper describes a coplanar waveguide coupled to two split ring resonators that, in turn, are loaded with two different reactive elements. By these means, balanced composite right/left-handed-like (CRLH-like) and also dual balanced composite right/left-handed-like (D-CRLH-like) responses can be obtained with the same structure showing opposite propagation characteristics. This behavior is achieved by simply varying one of the reactive elements, i.e., the capacitive or inductive load. The physical behavior of these transmission lines has been successfully explained by means of a single equivalent circuit. Besides, the proposed transmission lines have an extended bandwidth due to the balanced nature of the structure. The bandwidth of these lines can be electronically controlled using varactor diodes reverse-biased by an external DC voltage. Thus, a reconfigurable cell with CRLH-like and D-CRLH-like propagation has been designed and manufactured. Simulated and measured results show fractional bandwidths (FBW) from $0 \%$ (no transmission) to 9.3\% for simulations and from $0 \%$ (no transmission) to $8.7 \%$ for measurements. Undoubtedly, these new proposed transmission lines will be useful for designing reconfigurable devices that can be used in future communication systems such as radar, wireless applications, Global Positioning Systems (GPS), or RadioFrequency IDentification (RFID) systems, among others.
\end{abstract}

\section{INTRODUCTION}

In recent years a variety of transmission lines with new configurations has been presented. Some of these new configurations are related to left-handed transmission lines due to their unique properties [1]-[5]. The left-handed behavior is obtained when the host transmission line is either loaded with split-ring resonators (SRRs) [6]-[8] or their dual counterpart, the complementary split-ring resonator (CSRR) [9]-[12], as well as with reactive elements [13], [14]. In coplanar waveguide (CPW) technology, such propagation is reached by using SRRs coupled to the line and an inductive connection between the ground plane and the signal strip. The right-handed band that appears at higher frequencies can be generally controlled by connecting a microstrip stub to

This work was supported by the Ministerio de Economía y Competitividad, Spanish Goverment, under Research Project TEC2013-47037-C05-3-R and TEC2013-47037-C05-1-R, and by the Ministerio de Educación, Cultura y Deporte under the Fellowship Program for Training University Professors.

L. Martínez, A. L. Borja and A. Belenguer are with Departamento de Ingeniería Eléctrica, Electrónica, Automática y Comunicaciones, Universidad de Castilla-La Mancha, Escuela Politécnica de Cuenca, Campus Universitario, 16071 Cuenca, Spain, and Escuela Politécnica de Albacete, Av. de España, s/n, 02071 Albacete, Spain (e-mail: leticia.martinez@uclm.es; alejandro.lucas@uclm.es; angel.belenguer@uclm.es;). Vicente E. Boria is with Departamento de Comunicaciones, Universidad Politecnica de Valencia, 46022 Valencia, Spain(e-mail:vboria@dcom.upv.es). the ring [4]. Thus, a balanced line can be achieved since the left-handed band is not affected by the stub. This effect is explained considering that the stub directly modifies the existing capacitance between the ring and the coplanar line, because it is the origin of the right-handed propagation band [15]. Concurrently, the work presented in [16] showed that a dual behavior can be achieved connecting the two rings that form the SRR with an inductive connection. In addition to this research, different structures with reconfigurable responses in terms of bandwidth ( [17] from $\mathrm{FBW}=2.6 \%$ to $\mathrm{FBW}=5.2 \%$, [18] from $\mathrm{FBW}=54 \%$ to $\mathrm{FBW}=90 \%$ and [19] from $\mathrm{FBW}=$ $5 \%$ to $\mathrm{FBW}=10 \%$ ) have been presented. However, devices with wide reconfigurable bandwidths, low insertion loss and simple arrangements are still a challenge. This is mainly due to the difficulty of modifying and controlling the inter-resonator and line-to-resonator coupling.

This work aims to enhance previous designs, and includes improved reconfigurable responses in terms of bandwidth and control of the propagation characteristics. Specifically, we present a single structure exhibiting both behaviors (CRLHlike and D-CRLH-like propagation). To this purpose, the SRRs are simultaneously loaded with inductive (positive reactance) and capacitive (negative reactance) components. The outer ring of the SRRs is connected to an open-ended microstrip stub, and the inner ring to a shorted microstrip stub. Thus, D-CRLHlike or CRLH-like propagation can be achieved with the same configuration. In addition, varactor diode loaded SRRs are employed to obtain electronically controllable wide bandwidth responses with very simple designs.

This paper is structured as follows. Section II describes the design and characteristics of the basic cell ( e.g., size, substrate and metallization layer), as well as the components of the corresponding equivalent circuit. The comparison between the responses of the simulated cell and of the proposed equivalent circuit is also studied. Section III presents the results of several prototypes designed in the previous section. Different behaviors of the proposed cell with and without reconfiguration can be observed through measurements. Finally, the main conclusions are discussed in Section IV.

\section{BASIC CEll Description AND EQuivalent CiRCUit}

The equivalent circuit of the basic cell proposed in this paper is shown in Fig. 1. 


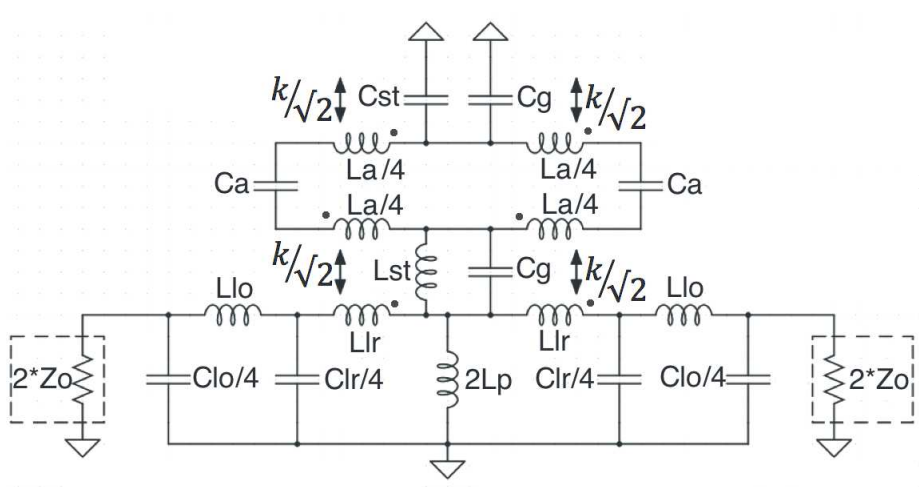

Fig. 1. Equivalent circuit for the cell proposed in this work.

The circuit has been obtained following the methods and processes described in references [4] and [15]. However, in the present case the ring resonators have been modified by adding an inductor connected to the inner ring, and a capacitor connected to the outer ring (see Fig. 2).

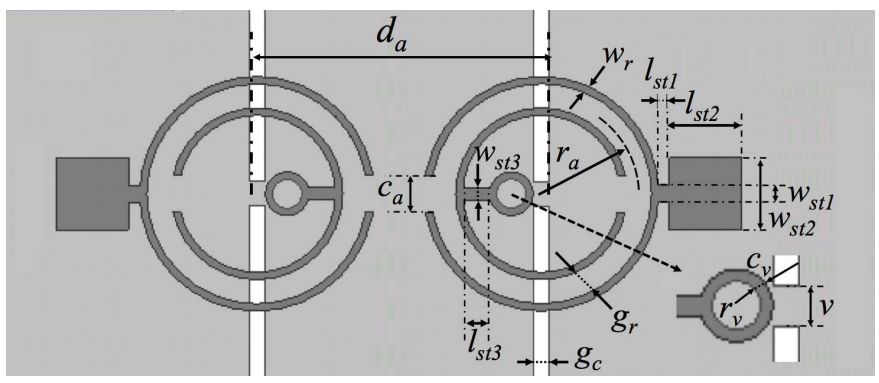

Fig. 2. Unit cell description. The unit cell is formed by a CPW line loaded with modified SRRs. Capacitive (open-ended stubs) and inductive (metallic via-holes) loads are connected to the outer and inner ring, respectively. Dark grey is bottom layer, light gray is top layer.

The inductive element connected to the inner ring is the most significative change between [4] and this new design. Nevertheless, this is not a meaningless change, since this is the key to achieve a cell with strong reconfiguration capabilities. In order to understand the importance of this change, the proposed equivalent circuit has been analyzed. In Fig. 1, one can see that the outer ring is connected to the ground through an equivalent capacitance $C_{g}+C_{s t}$. On the other hand, the inner ring is connected to the central strip of the coplanar waveguide through a parallel resonator $L_{s t} \| C_{g}$. However, this resonator is far below its resonance, so that the inductive element prevails and the capacitor, $C_{g}$, can be neglected $\left(C_{g}\right.$ is the capacitance between rings and ground, and it is very small). At the point where the inductance $L_{s t}$ is connected to the central strip, a very small inductance, $L_{p}$, connects this central strip with the ground plane. Since this inductance is really small, the inductance $L_{s t}$ is actually connected to the ground or, at least, this is a very good approximation. As a result, the centers of both rings are connected through a series LC resonator. At the design frequency of the cell, this LC resonator can be below its resonance, and therefore, exhibiting a negative reactance, i.e., a capacitive behavior. In this case, the cell holds a CRLH-like propagation, as in reference [4]. Conversely, the resonator can be above its resonant frequency at the design frequency of the cell. In this case, the resonator shows a positive equivalent reactance, i.e., an inductive type reactance. For that reason, a D-CRLH-like propagation can be expected, as in reference [16]. Finally, if the resonance coincides with the design frequency of the cell, both rings are indeed short-circuited and propagation is not possible, i.e., the icell virtually reflects all the power.

In order to prove this reasoning, the equivalent circuit is analyzed for different values of $C_{s t}$ using the circuit simulator of CST Microwave Studio ${ }^{\mathrm{TM}}$. When this capacitance is modified, the resonance of the equivalent series LC resonator that connects the rings is shifted. An equivalent result can be obtained if $L_{s t}$ is varied. However, practically, it is much easier to modify a capacitance than an inductance and, therefore, the first alternative is preferred.

Since a specific circuit has to be simulated, the values of the third column of Table I have been chosen to perform this parametric analysis.

TABLE I

EQuivalent CiRcuit ELEMENTS

\begin{tabular}{rrrrr}
\hline & \multicolumn{2}{c}{ CRLH-like } & \multicolumn{2}{c}{ D-CRLH-like } \\
\hline & Starting point & Optimized & Starting point & Optimized \\
\hline & & & & \\
$C_{s t}$ & $0.662 \mathrm{pF}$ & $0.688 \mathrm{pF}$ & $2.066 \mathrm{pF}$ & $1.707 \mathrm{pF}$ \\
$C_{g}$ & $0.560 \mathrm{pF}$ & $0.588 \mathrm{pF}$ & $0.531 \mathrm{pF}$ & $0.410 \mathrm{pF}$ \\
$L_{a}$ & $18.567 \mathrm{nH}$ & $18.567 \mathrm{nH}$ & $17.361 \mathrm{nH}$ & $17.361 \mathrm{nH}$ \\
$C_{a}$ & $0.351 \mathrm{pF}$ & $0.324 \mathrm{pF}$ & $0.331 \mathrm{pF}$ & $0.308 \mathrm{pF}$ \\
$L_{s t}$ & $0.901 \mathrm{nH}$ & $0.955 \mathrm{nH}$ & $0.994 \mathrm{nH}$ & $1.328 \mathrm{nH}$ \\
$L_{p}$ & $0.173 \mathrm{nH}$ & $0.173 \mathrm{nH}$ & $0.173 \mathrm{nH}$ & $0.173 \mathrm{nH}$ \\
$L_{l r}$ & $1.727 \mathrm{nH}$ & $1.727 \mathrm{nH}$ & $1.638 \mathrm{nH}$ & $1.638 \mathrm{nH}$ \\
$L_{l o}$ & $1.750 \mathrm{nH}$ & $1.750 \mathrm{nH}$ & $1.840 \mathrm{nH}$ & $1.840 \mathrm{nH}$ \\
$C_{l r}$ & $0.688 \mathrm{pF}$ & $0.688 \mathrm{pF}$ & $0.652 \mathrm{pF}$ & $0.652 \mathrm{pF}$ \\
$C_{l o}$ & $0.696 \mathrm{pF}$ & $0.696 \mathrm{pF}$ & $0.732 \mathrm{pF}$ & $0.732 \mathrm{pF}$ \\
$k$ & 0.375 & 0.330 & 0.375 & 0.348 \\
\hline \multicolumn{5}{c}{}
\end{tabular}

The results of this parametric analysis are shown in Figs. 3 and 4 . These results prove that by modifying the capacitance connected to the external ring, it is possible to control the behavior of the cell, as expected. The circuit, for small values of $C_{s t}$, holds a CRLH-like propagation. As this capacitor is increased, the right-handed band shifts down in frequency until it overlaps with the left-handed band. At this time, the reactance of the capacitor $C_{s t}$ cancels the inductive reactance of $L_{s t}$, and the ring is shorted. Consequently, the input electromagnetic signal is reflected. If the capacitor value is still increased, the inductive effect prevales and a dual transmission is obtained. In this study, the value of $C_{s t}$ has changed from $0.69 \mathrm{pF}$ to 2.8 pF. From $0.69 \mathrm{pF}$ to $1.2 \mathrm{pF}$ a CRLH-like behavior is observed. Then, the circuit has a stopband behavior. Finally, from $1.9 \mathrm{pF}$ to $2.8 \mathrm{pF}$ the circuit behaves as a D-CRLH-like cell. 


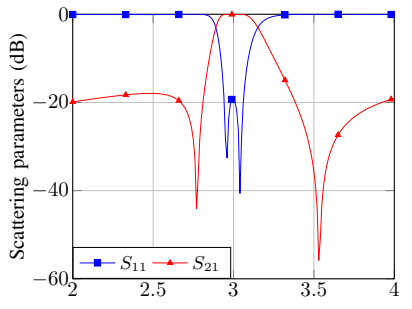

Frequency $(\mathrm{GHz})$

(a) Capacitor $C_{s t}=0.69 \mathrm{pF}$.

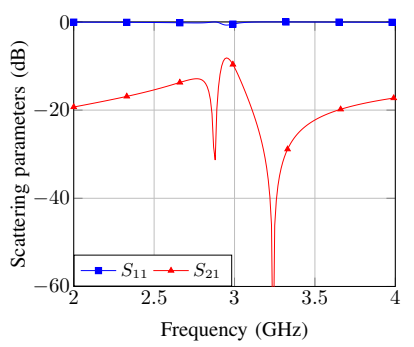

(c) Capacitor $C_{s t}=1.30 \mathrm{pF}$.

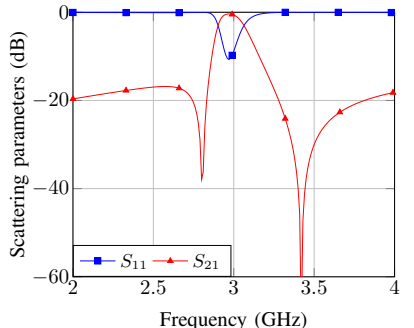

(b) Capacitor $C_{s t}=0.90 \mathrm{pF}$.

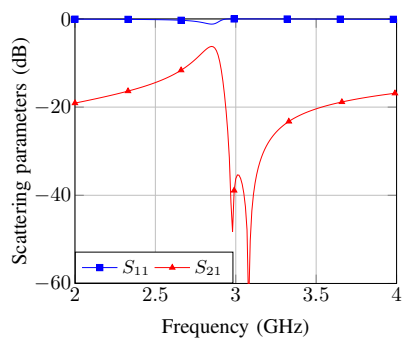

(d) Capacitor $C_{s t}=1.60 \mathrm{pF}$
Fig. 3. CRLH-like equivalent circuit simulated responses. Scattering parameters obtained for different values of $C_{s t}$. Results obtained after optimization (see third column of Table I).

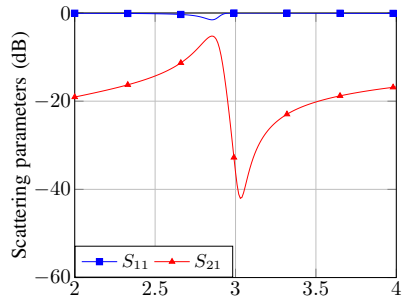

Frequency $(\mathrm{GHz})$

(a) Dimension $C_{s t}=1.65 \mathrm{pF}$.

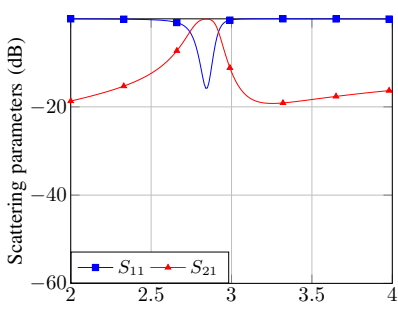

Frequency $(\mathrm{GHz})$

(c) Dimension $C_{s t}=2.40 p F$.

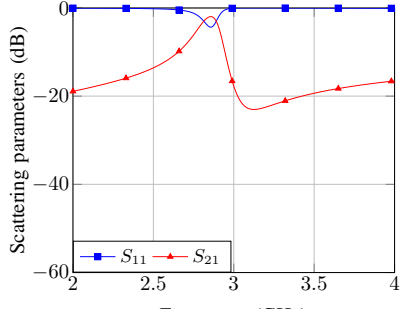

Frequency $(\mathrm{GHz})$

(b) Dimension $C_{s t}=1.90 \mathrm{pF}$.

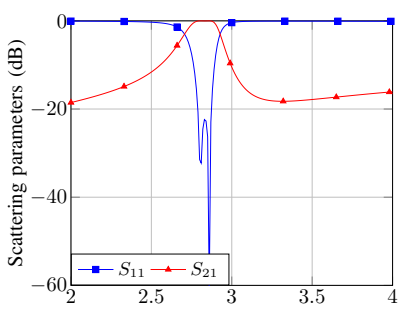

Frequency $(\mathrm{GHz})$

(d) Dimension $C_{s t}=2.80 \mathrm{pF}$.
Fig. 4. D-CRLH-like equivalent circuit simulated responses. Scattering parameters obtained for different values of $C_{s t}$. Results obtained after optimization (see third column of Table I).

The basic cell associated to the equivalent circuit previously proposed consists of a CPW combined with a pair of SRRs located on the opposite plane of the line, see Fig.2. In this physical arrangement, $C_{s t}$ is implemented with an open-ended stub of dimensions $l_{s t 2}$ and $w_{s t 2}$ connected to the external part of the ring. This open-ended stub behaves as a capacitor and it is connected between the outer ring and the ground, and its capacitance can be calculated as in [4] and [20]. $L_{s t}$ can be synthesized with a shorted stub. $L_{s t}$ is, therefore, the sum of the inductance of the shorted stub, which can be determined by the dimensions $l_{s t 3}$ and $w_{s t 3}$, and the inductance of the via or vias at the end of the stub [21]. This shorted stub is connected between the inner ring and the line.
TABLE II

Cell Dimensions

\begin{tabular}{crr}
\hline & CRLH-like & D-CRLH-like \\
\hline & & \\
$l_{s t 1}$ & $0.30 \mathrm{~mm}$ & $0.42 \mathrm{~mm}$ \\
$w_{s t 1}$ & $0.40 \mathrm{~mm}$ & $0.42 \mathrm{~mm}$ \\
$l_{s t 2}$ & $3.00 \mathrm{~mm}$ & $8.00 \mathrm{~mm}$ \\
$w_{s t 2}$ & $3.00 \mathrm{~mm}$ & $6.00 \mathrm{~mm}$ \\
$l_{s t 3}$ & $1.30 \mathrm{~mm}$ & $1.50 \mathrm{~mm}$ \\
$w_{s t 3}$ & $0.20 \mathrm{~mm}$ & $0.20 \mathrm{~mm}$ \\
$g_{r}$ & $0.40 \mathrm{~mm}$ & $0.40 \mathrm{~mm}$ \\
$w_{r}$ & $0.42 \mathrm{~mm}$ & $0.40 \mathrm{~mm}$ \\
$c_{a}$ & $0.80 \mathrm{~mm}$ & $0.80 \mathrm{~mm}$ \\
$r_{v}$ & $0.30 \mathrm{~mm}$ & $0.30 \mathrm{~mm}$ \\
$c_{v}$ & $0.30 \mathrm{~mm}$ & $0.30 \mathrm{~mm}$ \\
$r_{a}$ & $4.05 \mathrm{~mm}$ & $3.83 \mathrm{~mm}$ \\
$d_{a}$ & $10.65 \mathrm{~mm}$ & $10.65 \mathrm{~mm}$ \\
$v$ & $1.00 \mathrm{~mm}$ & $1.00 \mathrm{~mm}$ \\
$g_{c}$ & $0.65 \mathrm{~mm}$ & $0.65 \mathrm{~mm}$ \\
& & \\
\hline
\end{tabular}

The physical dimensions of the final design, obtained following the procedure described in [6] and [16], are shown in Table II. It is worthwhile mentioning that the ring radius $\left(r_{a}\right)$ has different values for the CRLH-like and the D-CRLH-like designs. As it can be observed in Figs. 3 and 4, the pass-band response for both cells appears at different central frequencies, at $3 \mathrm{GHz}$ for the CRLH-like line and at $2.86 \mathrm{GHz}$ for the D-CRLH-like line. Therefore, the radius of the resonator has been slightly decreased in the case of the D-CRLH-like basic cell to shift the frequency response to $3 \mathrm{GHz}$. The cells have been implemented using a Rogers RO4003C ${ }^{\mathrm{TM}}$ substrate $\left(\epsilon_{r}=\right.$ $3.55)$ of $1.524 \mathrm{~mm}$ tickness with a copper metallization layer of $35 \mu \mathrm{m}$.

In order to validate the proposed configuration, the circuit results are compared with a full-wave simulation of the physical cell without losses using, again, CST Microwave Studio $^{\mathrm{TM}}$. As it can be seen in Fig. 5, the values calculated for each component (see Table I) are a good starting point for an optimization process that converges to an acceptable solution. Nevertheless, these values have to be optimized in order to obtain more accurate responses. Some components of the circuit have been adjusted by an optimization process to match the results obtained from the full-wave simulations. These components are: $C_{s t}, C_{g}, C_{a}$ and $L_{s t}$. A NelderMead Simplex Algorithm was used with the next goals: $\left|S_{11 \text { circuit }}-S_{11 \text { sim }}\right| \leq 0.01$ to match the responses within pass-band, and $\left|S_{21 \text { circuit }}-S_{21 \text { sim }}\right| \leq 0.01$ to match the responses out of the pass-band. The values obtained after optimization are shown in Table I (third and fifth columns). In Fig. 6 the optimized results of the CRLH-like and DCRLH-like circuits are observed. In both types of cell, a pass-band centered at $3 \mathrm{GHz}$ is obtained. The equivalent circuit models accurately the real cell performance near the resonance of the rings. Nevertheless, the more we move away from this resonance, the response of the equivalent circuit is progressively degraded. Two transmission zeros are only observed at both sides of the pass-band of the CRLH-like cell. As it will be shown in the next section, this behavior is due to the fact that first a left-handed propagation band and then a right-handed propagation band are obtained. These zeros 
cannot be observed in the D-CRLH-like cell, because first the right-handed band and then the left-handed band appear, cancelling in this way these zeros, which is in agreement with the results previously published in [22].

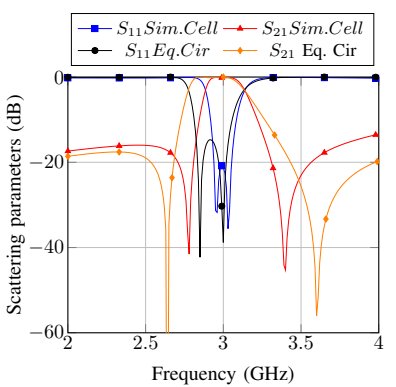

(a) CRLH-like Circuit.

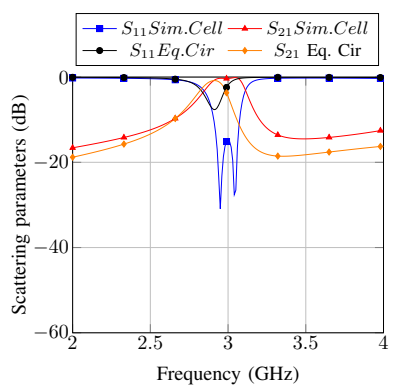

(b) D-CRLH-like Circuit.
Fig. 5. Simulated circuit (before optimization) and full-wave scattering parameters.

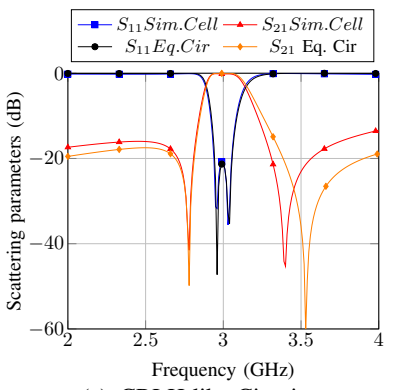

(a) CRLH-like Circuit.

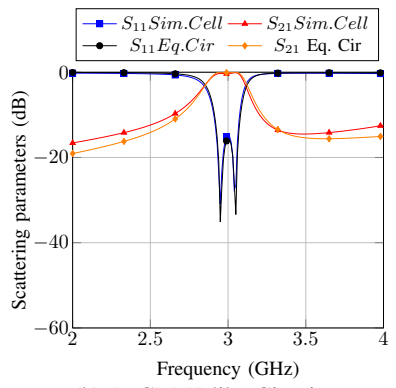

(b) D-CRLH-like Circuit.

Fig. 6. Simulated circuit (after optimization) and full-wave scattering parameters.

\section{EXPERIMENTAL RESULTS}

In this section, three prototypes have been manufactured and measured in order to validate the designs presented previously. Firstly, the basic cell presented in Section II has been experimentally validated using two configurations, i.e., SRRs with different open-ended stubs. As it will be shown, if the size of the stub is modified, the capacitor $C_{s t}$ varies and the CPW behaves as a CRLH-like or D-CRLH-like transmission line. $C_{s t}$ only affects the position of the right-handed band, while the left-handed one remains unaltered. In this way, the behavior of the cell and also its operational bandwidth can be controlled. Once this fact has been verified, an electronically reconfigurable cell has been designed and investigated. In this case, the open-ended stub is replaced by a variable capacitance obtained by means of a reverse-biased varactor diode.

\section{A. Experimental Validation of the Basic Cell}

In this subsection, the measured frequency responses of two basic cells with different open-ended stubs are presented. The prototypes, whose dimensions are specified in Table II, have been manufactured using a mechanical milling process, see Fig. 7. To measure these cells, a tapered transition to a narrower coplanar line has been added in order to solder an SMA connector with an input impedance of $50 \Omega$. This input/output taper is a linear transition of $9 \mathrm{~mm}$ length between the internal line and the feeding line. The outer coplanar waveguide, where the connectors are soldered, is composed of a central strip of $5 \mathrm{~mm}$ and a gap of $0.65 \mathrm{~mm}$ in the Rogers RO4003C ${ }^{\mathrm{TM}}$ design.

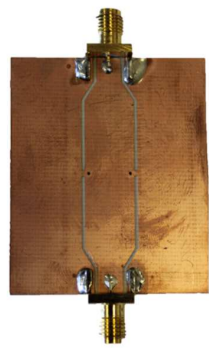

(a)

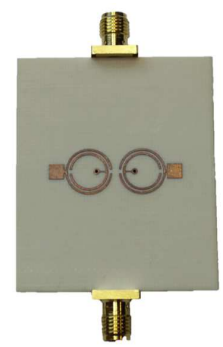

(b)

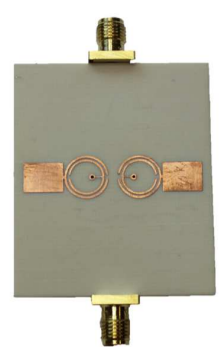

(c)
Fig. 7. Photographs of the two fabricated prototypes designed in Rogers RO4003C ${ }^{\mathrm{TM}}$ : (a) Top view, (b) Bottom view with open-ended stub length and width of $3 \mathrm{~mm}$ and $3 \mathrm{~mm}$, respectively, and (c) Bottom view with open-ended stub length and width of $8 \mathrm{~mm}$ and $6 \mathrm{~mm}$, respectively.

In Fig. 8, simulated results, considering losses, and measurements are compared.

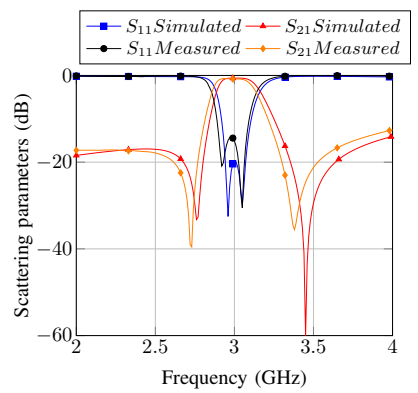

(a) CRLH-like Circuit.

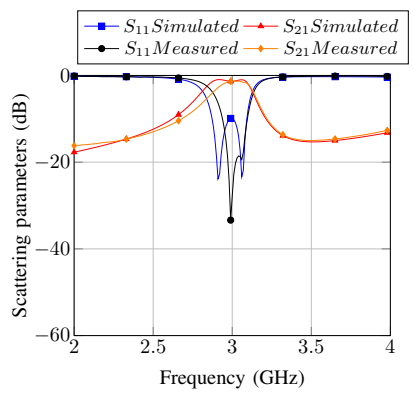

(b) D-CRLH-like Circuit.
Fig. 8. Scattering parameters. Comparison between measurements and simulated results.

The simulated cells have been excited with waveguide ports, meanwhile a radiation box has been used to simulate the boundary conditions. The measurements were obtained with an Anritsu vector network analizer (Fig. 9), which has been calibrated with a custom TRL calibration kit in order to deembed effects of the connectors and the coplanar tapers, see Fig. 10. 


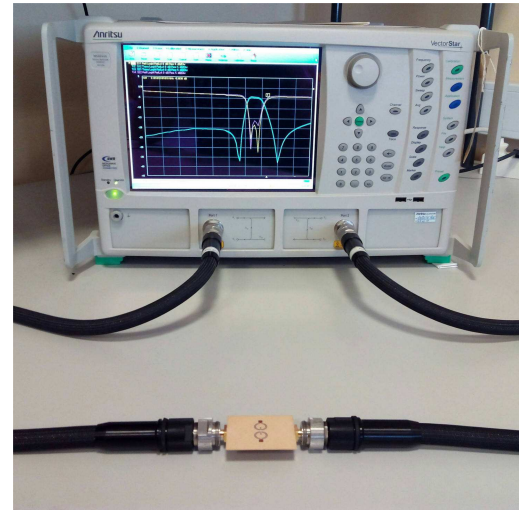

Fig. 9. Experimental set-up of the basic cell.

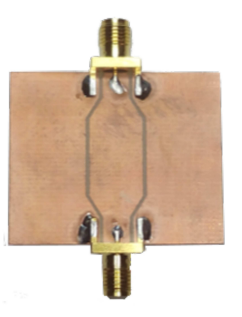

(a) Thru

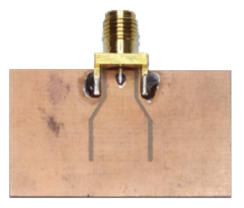

(b) Reflect

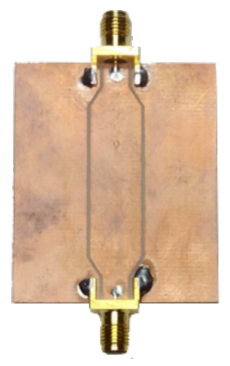

(c) Line
Fig. 10. TRL Calibration Kit designed in Rogers RO4003C ${ }^{\mathrm{TM}}$ cell.

Different behaviors can be seen in Figs. 8(a) and 8(b). In Fig. 8(a), a CRLH-like behavior with a center frequency of $3 \mathrm{GHz}, 9 \%$ fractional bandwidth, and two transmission zeros, one above and one below the center frequency is observed. In Fig. 8(b) a D-CRLH-like response with the same center frequency, $8.3 \%$ fractional bandwidth, and without transmission zeros due to its dual behavior is obtained. The simulated and measured insertion losses (at the center frequency) are shown in Table III for each case.

TABLE III

INSERTION LOSS

\begin{tabular}{lcc}
\hline & CRLH-like & D-CRLH-like \\
\hline Simulated & $0.62 \mathrm{~dB}$ & $1.34 \mathrm{~dB}$ \\
Measured & $0.82 \mathrm{~dB}$ & $1.37 \mathrm{~dB}$ \\
& & \\
\hline
\end{tabular}

The CRLH-like and D-CRLH-like behaviors can also be observed in Fig. 11, where the dispersion diagram of the cells are represented using the following equation [23]:

$$
\beta l_{l}=\cos ^{-1}\left(\frac{1-s_{11} s_{22}+s_{12} s_{21}}{2 s_{21}}\right)
$$

In the CRLH-like cell, Fig. 11(a), it is seen that below the center frequency of the pass-band, the phase decreases as the frequency increases, which denotes a left-handed behavior. Above this frequency the phase increases obtaining a righthanded propagation. In the D-CRLH-like cell, Fig. 11(b), it can be seen, first, the right-handed behavior of the line, below the pass-band, followed by the left-handed behavior above the pass-band. CRLH-like and D-CRLH-like behavior of the lines are thus validated.

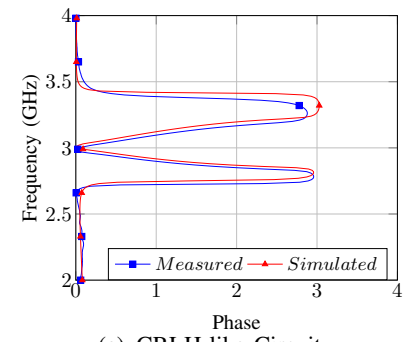

(a) CRLH-like Circuit.

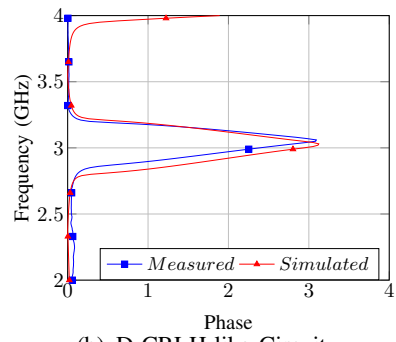

(b) D-CRLH-like Circuit.
Fig. 11. Dispersion diagram of the fabricated prototypes.

\section{B. Electronically Controlled Transmission Line}

A new basic cell with electronically reconfigurable capabilities is presented in this subsection. The general schematic of the structure is the same of Fig. 2, just the SRR configuration is modified to introduce a variable capacitance. Thus, the capacitive stub (defined by $l_{s t 2}$ and $w_{s t 2}$ ) is replaced by a varactor diode connected to ground. The biasing circuit is formed by two high value resistances that prevent RF coupling and two metallic pads used to apply a DC voltage, see Fig. 12(a). Also, a fabricated prototype and a measurement set-up are illustrated in Figs. 12(b) and 12(c). The use of varactor diodes allows to control the capacitive coupling between the ring and the transmission line. Therefore, the right-handed resonance can be shifted depending on the biasing voltage, obtaining the desired transmission bandwidth. In addition, it is possible to switch between CRLH-like or D-CRLH-like propagation or even cancel transmission. In this particular case, a varactor BB857 model with capacitance values ranging from $0.45 \mathrm{pF}$ to $7.2 \mathrm{pF}$ is employed.

Simulated and measured scattering parameters of three different cases, i.e., CRLH-like propagation, no propagation, or D-CRLH-like propagation, are shown in Figs. 13, 14 and 15, respectively. These figures show that by varying the external voltage that controls the polarity of the varactor, it is possible to reconfigure the bandwidth, change the propagation mode or even to avoid transmission. In particular, for a biasing voltage of $30 \mathrm{~V}(0.5 \mathrm{pF}$ associated nominal capacitance), a CRLH-like behavior is obtained in the measurement. If the biasing voltage is decreased to $14 \mathrm{~V}$, the associated nominal capacitance is now $0.8 \mathrm{pF}$ and there is no transmission. With biasing voltages below $9 \mathrm{~V}$ (associated nominal capacitances above $1.1 \mathrm{pF}$ ), DCRLH-like behavior is obtained. The reconfigurable fractional bandwidth obtained varies from $0 \%$ (no transmission) to $8.7 \%$ with a CRLH-like behavior and to $6.5 \%$ with a D-CRLH-like behavior. The frequency range covered for this basic cell with CRLH-like propagation is $260 \mathrm{MHz}$ starting from $2.85 \mathrm{GHz}$ to $3.11 \mathrm{GHz}$ and with D-CRLH-like propagation is $180 \mathrm{MHz}$ starting from $2.65 \mathrm{GHz}$ to $2.83 \mathrm{GHz}$. 


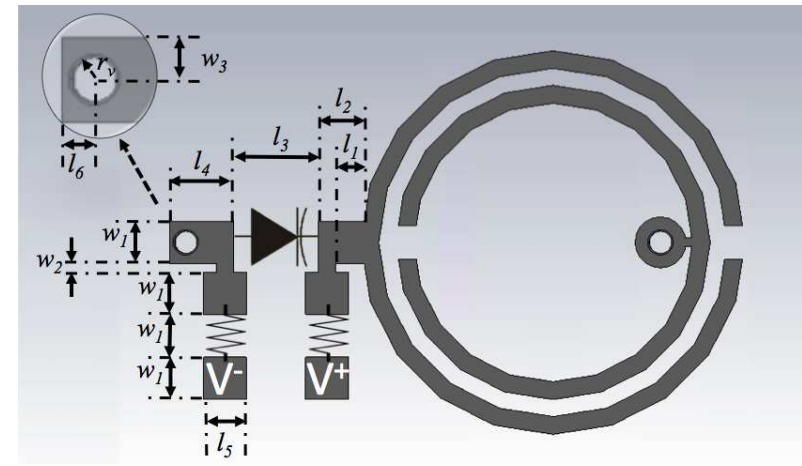

(a) Varactor diode loaded split ring resonator configuration. Dimensions: $w_{1}=1 \mathrm{~mm}, w_{2}=0.2 \mathrm{~mm}, w_{3}=0.5 \mathrm{~mm}, l_{1}=0.68 \mathrm{~mm}, l_{2}=1.08 \mathrm{~mm}, l_{3}=2 \mathrm{~mm}$, $l_{4}=1.5 \mathrm{~mm}, l_{5}=1 \mathrm{~mm}, l_{6}=0.38 \mathrm{~mm}, r_{a}=3.9 \mathrm{~mm}, l_{s t 3}=0.15 \mathrm{~mm}$. The other dimensions of the circuit are equal to the cell CRLH-like (see Table II)

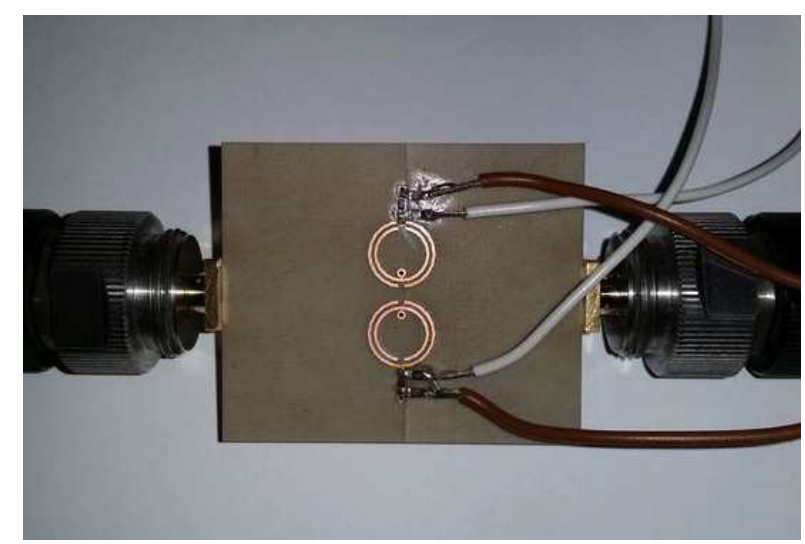

(b) Photograph of the varactor loaded fabricated prototype designed in Rogers $4003 \mathrm{C}^{\mathrm{TM}}$.

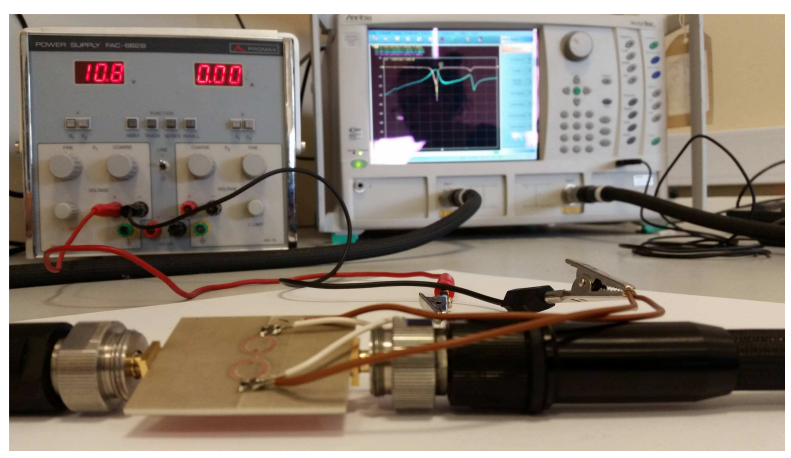

(c) Experimental Set-up of the Reconfigurable Cell

Fig. 12. Prototype and Experimental Set-up of the Reconfigurable Cell.

The insertion losses at the center frequency for simulations and measurements are shown in Table IV. The table shows that the measured losses are higher than the simulated ones. However, in all cases insertion losses are below $3 \mathrm{~dB}$. To the best of the authors' knowledge, this result is one of the widest reconfigurable bandwidths obtained with CRLH-like or DCRLH-like transmission lines.

Some small discrepancies between simulated and measured results, including frequency displacements, insertion loss variations and SRR-to-ground capacitances disagreement, are noticed. It can be due to parasitic capacitances and welding imperfections not considered during simulations. In any case, the agreement between experimental data and full-wave simulations is very good.

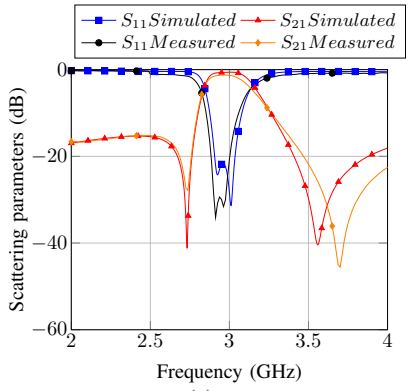

(a)

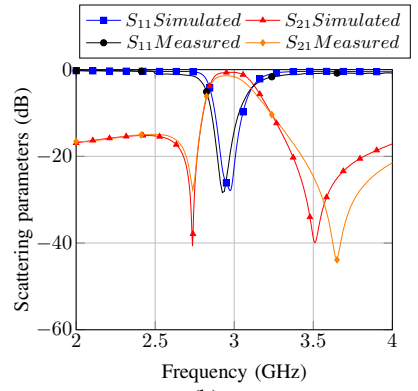

(b)
Fig. 13. CRLH-like responses. Scattering parameters obtained for different reverse-biasing voltages. (a) Measured: Reverse-biased voltage $V=30 \mathrm{~V}$ Nominal associated capacity $C=0.45 p F$. Simulated: $C=0.37 p F$. (b) Measured: Reverse-biased voltage $V=24 \mathrm{~V}$. Nominal associated capacity $C=0.6 p F$. Simulated: $C=0.38 p F$.

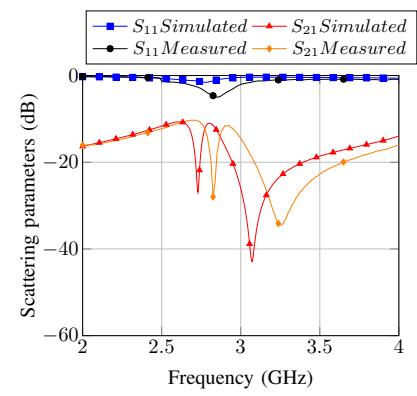

Fig. 14. Scattering parameters obtained for $14 \mathrm{~V}$ reverse-biasing voltage. Measured: Nominal associated capacity $C=0.8 \mathrm{pF}$. Simulated: $C=0.73$ $p F$.

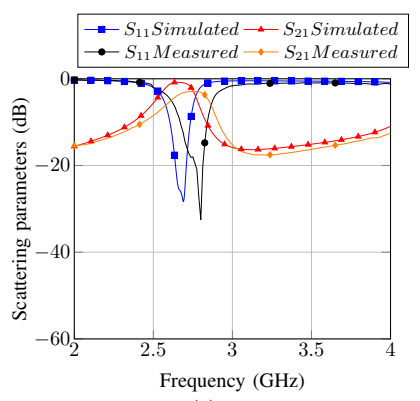

(a)

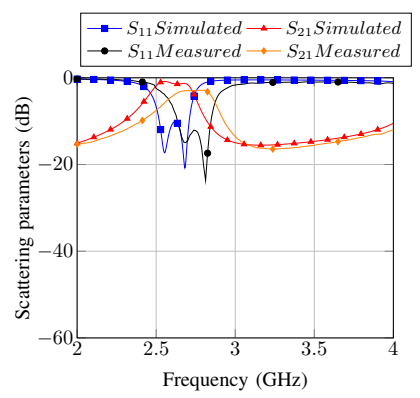

(b)
Fig. 15. D-CRLH-like responses. Scattering parameters obtained for different reverse-biasing voltages. (a) Measured: Reverse-biased voltage $V=9.5 \mathrm{~V}$. Nominal associated capacity $C=1 \mathrm{pF}$. Simulated: $C=0.96 \mathrm{pF}$. (b) Measured: Reverse-biased voltage $V=9 \mathrm{~V}$. Nominal associated capacity $C=1.1 \mathrm{pF}$. Simulated: $C=1.12 \mathrm{pF}$.

TABLE IV

INSERTION Loss - RECONFIGURABLE DEVICE

\begin{tabular}{lcc}
\hline & CRLH-like & D-CRLH-like \\
\hline Simulated & $0.62 \mathrm{~dB}$ & $1.29 \mathrm{~dB}$ \\
Measured & $1.26 \mathrm{~dB}$ & $2.86 \mathrm{~dB}$ \\
& & \\
\hline
\end{tabular}


Fig. 16 shows the dispersion diagram for two cases having CRLH-like and D-CRLH-like propagation. As it can be seen, the results obtained are coherent with those achieved in Figs. 13(a) and 15(b), thus validating the correct performance of the electronically reconfigurable prototype.
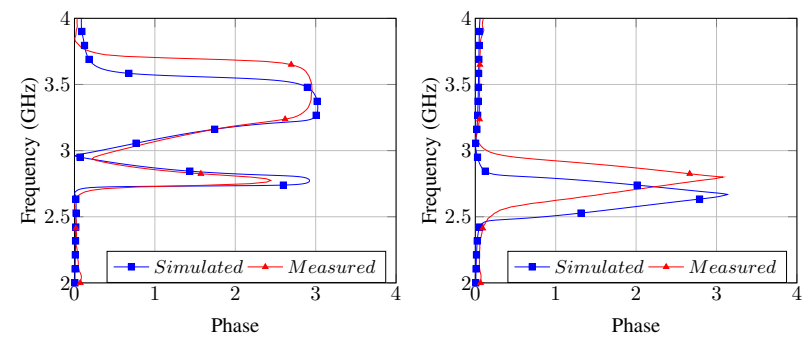

(a) CRLH-like Circuit. Reverse-biased (b) D-CRLH-like Circuit. Reversevoltage $V=30 \mathrm{~V}$.

biased voltage $V=9 \mathrm{~V}$.

Fig. 16. Dispersion diagrams of the varactor loaded fabricated prototypes.

\section{Conclusions}

In this paper, a coplanar waveguide line combined with reactively loaded SRRs has been presented. If the cell structure is maintained, but the capacitance of the open-ended stub is modified (changing its dimensions -total surface over the cell), two different balanced behaviors are achieved: CRLH-like or D-CRLH-like propagation. A general equivalent circuit able to model both behaviors has also been proposed. A good starting point for the optimization process is achieved with the estimation of the equivalent circuit elements. Then, these elements have been adjusted to match full-wave simulations. Two different prototypes have been manufactured in order to experimentally validate the design of the CRLH-like and D-CRLH-like cells. In addition, an electronically controllable structure has also been fabricated and measured. This device is able to achieve reconfigurable bandwidth responses with fractional bandwidths between $0 \%$ (no transmission) and $8.3 \%$. Besides, it is capable to behave as a CRLH-like and D-CRLHlike transmission line simultaneously. These transmission lines can be used in multiple communication applications such as radar, wireless, GPS, or RFID systems. The main advantages of the reconfigurable structure are the possibility to cover a wide reconfigurable bandwidth (from full rejection to transmission) and control the characteristics of the propagation mode in real time. To the best of the author's knowledge, this is the first time that this kind of reconfiguration and control has been achieved. Finally, as future work, other electronic reconfiguration could be added to this current design. For instance, reconfiguration of the center frequency would allow to operate for both CRLH-like and D-CRLH-like modes at the same frequency, or preserve the central frequency when the bandwidth is modified.

\section{REFERENCES}

[1] F. Martín, J. Bonache, F. Falcone, M. Sorolla, and R. Marqués, "Split ring resonator-based left-handed coplanar waveguide," Applied Physics Letters, vol. 83, no. 22, pp. 4652-4654, 2003.

[2] C. Caloz, "Dual composite right/left-handed (D-CRLH) transmission line metamaterial," IEEE Microwave and Wireless Components Letters, vol. 16 , no. 11 , pp. $585-587$, Nov. 2006.
[3] A. Belenguer, A. L. Borja, and V. E. Boria, "Balanced dual composite right/left-handed microstrip line with modified complementary split-ring resonators," IEEE Antennas and Wireless Propagation Letters, vol. 12, pp. 880-883, 2013.

[4] V. Sanz, A. Belenguer, L. Martinez, A. L. Borja, J. Cascon, and V. E. Boria, "Balanced right/left-handed coplanar waveguide with stub loaded split ring resonators," IEEE Antennas and Wireless Propagation Letters, vol. 13, pp. 193-196, 2014.

[5] F. Martín, Artificial Transmission Lines for RF and Microwave Applications. John Wiley, 2015.

[6] R. Marqués, F. Martín, and M. Sorolla, Metamaterials with Negative Parameters: Theory, Design and Microwave Applications. John Wiley \& Sons, 2008.

[7] A. L. Borja, J. Carbonell, V. E. Boria, and D. Lippens, "Highly selective left-handed transmission line loaded with split ring resonators and wires," Appl. Phys. Lett., vol. 94, no. 14, 2009.

[8] I. Gil, J. Bonache, J. Garcia-Garcia, F. Falcone, and F. Martin, "Metamaterials in microstrip technology for filter applications," in IEEE Antennas and Propagation Society International Symposium, vol. 1A, July 2005, pp. $668-671$ Vol. $1 \mathrm{~A}$.

[9] M. Gil, J. Bonache, I. Gil, J. Garcia-Garcia, and F. Martin, "On the transmission properties of left-handed microstrip lines implemented by complementary split rings resonators," International Journal of Numerical Modelling: Electronic Networks, Devices and Fields, vol. 19, no. 1, pp. $87-103,2006$.

[10] M. Gil, J. Bonache, J. Garcia-Garcia, J. Martel, and F. Martin, "Composite right/left-handed metamaterial transmission lines based on complementary split-rings resonators and their applications to very wideband and compact filter design," IEEE Transactions on Microwave Theory and Techniques, vol. 55, no. 6, pp. 1296 -1304, Jun. 2007.

[11] M. Gil, J. Bonache, and F. Martin, "Synthesis and applications of new left handed microstrip lines with complementary split-ring resonators etched on the signal strip," IET Microwaves, Antennas Propagation, vol. 2, no. 4, pp. $324-330$, Jun. 2008.

[12] M. Duran-Sindreu, A. Velez, F. Aznar, G. Siso, J. Bonache, and F. Martin, "Applications of open split ring resonators and open complementary split ring resonators to the synthesis of artificial transmission lines and microwave passive components," IEEE Transactions on Microwave Theory and Techniques, vol. 57, no. 12, pp. 3395 -3403, Dec. 2009.

[13] C. Caloz and T. Itoh, "Application of the transmission line theory of left-handed (LH) materials to the realization of a microstrip "LH line"," in IEEE Antennas and Propagation Society International Symposium, vol. 2, 2002, pp. $412-415$ vol.2.

[14] A. Grbic and G. V. Eleftheriades, "Experimental verification of backward-wave radiation from a negative refractive index metamaterial," Journal of Applied Physics, vol. 92, no. 10, pp. 5930 -5935, Nov. 2002.

[15] V. Sanz, A. Belenguer, A. L. Borja, J. Cascon, H. Esteban, and V. E. Boria, "Broadband equivalent circuit model for a coplanar waveguide line loaded with split ring resonators," International Journal of Antennas and Propagation, vol. 2012, no. 613518, 2012.

[16] A. Belenguer, J. Cascon, A. L. Borja, H. Esteban, and V. E. Boria, "Dual composite right/left-handed coplanar waveguide transmission line using inductively connected split-ring resonators," IEEE Transactions on Microwave Theory and Techniques, vol. 60, no. 10, pp. 3035-3042, 2012.

[17] F. Gentili, L. Pelliccia, F. Cacciamani, P. Farinelli, and R. Sorrentino, "Rf mems bandwidth-reconfigurable hairpin filters bandwidth-reconfigurable hairpin filters," in Asia Pacific Microwave Conference Proceedings, Dec 2012, pp. 735-737.

[18] J. Y. Chen, H. J. Tsai, and N. W. Chen, "Bandwidth reconfigurable microwave bandpass filter," in IEEE MTT-S International Microwave Symposium Digest (IMS), June 2011, pp. 1-4.

[19] D. Psychogiou and D. Peroulis, "Reconfigurable bandpass filter with center frequency and bandwidth control," Microwave and Optical Technology Letters, vol. 55, no. 11, pp. 2745-2750, 2013.

[20] B. C. Wadell, Transmission Line Design Handbook. Artech House, 1991.

[21] M. Goldfarb and R. Pucel, "Modeling via hole grounds in microstrip," IEEE Microwave and Guided Wave Letters, vol. 1, no. 6, pp. 135-137, June 1991.

[22] J. Carbonell, A. Borja, V. Boria, and D. Lippens, "Duality and superposition in split-ring-resonator-loaded planar transmission lines," IEEE Antennas and Wireless Propagation Letters, vol. 8, pp. 886-889, 2009.

[23] C. Caloz and T. Itoh, Electromagnetic Metamaterials: Transmission Line Theory and Microwave Applications. Wiley, 2005. 


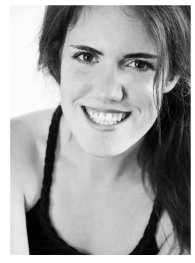

Leticia Martinez Cano received the Technical Telecommunication Engineering degree from the Universidad de Castilla-La Mancha (UCLM), Spain in 2009, and the Telecommunication Master from the Universidad Politécnica de Madrid (UPM), Spain, in 2012. She is currently working toward the Ph. D. degree at UCLM under the Fellowship Program for Training University Professors. Her research interests include substrate integrate waveguide, EM metamaterials and reconfigurable devices and their applications in microwave.

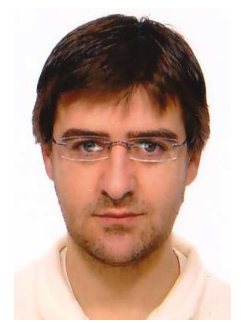

Alejandro L. Borja (M'15) received the M.Sc. degree in telecommunication engineering and the Ph.D. degree from the Universidad Politecnica de Valencia, Valencia, Spain, in 2004 and 2009, respectively. From 2005 to 2006, he was with the University of Birmingham, Birmingham, U.K. From 2007 to 2008, he was with the Universite de Lille 1, Lille, France. Since 2009, he has been with the Universidad de Castilla-La Mancha, Spain, where he is an Assistant Lecturer. He has published more than 50 papers in peer-reviewed international journals and conference proceedings, and frequently acts as a reviewer for several technical publications. In 2012, he served as a Lead Guest Editor for a special issue of the International Journal of Antennas and Propagation. His research interests include EM metamaterials, substrate integrate waveguide, and reconfigurable devices and their applications in microwave and millimetric bands.

Dr. Borja was the recipient of the 2008 CST short paper award.

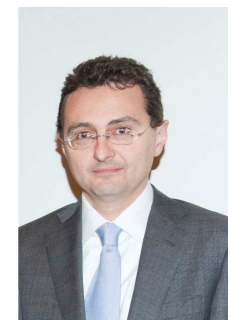

Vicente E. Boria (S'91-A'99-SM'02) was born in Valencia, Spain, on May 18, 1970. He received his Ingeniero de Telecomunicación degree (with firstclass honors) and the Doctor Ingeniero de Telecomunicación degree from the Universidad Politécnica de Valencia, Valencia, Spain, in 1993 and 1997, respectively. In 1993 he joined the Departamento de Comunicaciones, Universidad Politécnica de Valencia, where he has been Full Professor since 2003. In 1995 and 1996, he was holding a Spanish Trainee position with the European Space Research and Technology Centre, European Space Agency (ESTEC-ESA), Noordwijk, The Netherlands, where he was involved in the area of EM analysis and design of passive waveguide devices. He has authored or co-authored 10 chapters in technical textbooks, 135 papers in refereed international technical journals, and over 180 papers in international conference proceedings. His current research interests are focused on the analysis and automated design of passive components, left-handed and periodic structures, as well as on the simulation and measurement of power effects in passive waveguide systems. Dr. Boria has been a member of the IEEE Microwave Theory and Techniques Society (IEEE MTT-S) and the IEEE Antennas and Propagation Society (IEEE AP-S) since 1992. He is member of the Editorial Boards of the IEEE Transactions on Microwave Theory and Techniques, IEEE Microwave and Wireless Components Letters, Proceeding of the IET (Microwaves, Antennas and Propagation), IET Electronics Letters and Radio Science. Presently, he serves as Associate Editor of IEEE Microwave and Wireless Components Letters and IET Electronics Letters. He is also a member of the Technical Committees of the IEEE-MTT International Microwave Symposium and of the European Microwave Conference.

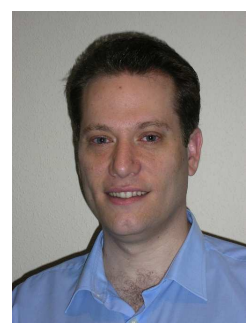

Angel Belenguer (M'04-SM'14) received his degree in telecommunications engineering from the Universidad Politécnica de Valencia (UPV), Spain, in 2000, and his Ph.D. degree, also from the UPV, in 2009. He joined the Universidad de Castilla-La Mancha in 2000, where he is now Profesor Titular de Universidad in the Departamento de Ingenieria Electrica, Electronica, Automatica y Comunicaciones. He has authored or co-authored more than 50 papers in peer-reviewed international journals and conference proceedings and frequently acts as a reviewer for several international technical publications. His research interests include methods in the frequency domain for the full-wave analysis of open-space and guided multiple scattering problems, the application of accelerated solvers or solving strategies (like grouping) to new problems or structures, EM metamaterials, and Substrate Integrated Waveguide (SIW) devices and their applications. 